\title{
Postura, tônus, pressão e mobilidade de lábios e língua em crianças respiradoras orais: análise comparativa da pressão, inspeção oral e dados de anamnese
}

\section{Amanda G. Larco*, Maria Fernanda Bagarollo}

\section{Resumo}

A respiração oral pode ser causada por diversos fatores, entre eles a hipertrofia de tonsilas palatina e faríngeas. Para que o padrão respiratório seja reestabelecido é realizada a adenotonsilectomia e reabilitação fonoaudiológica, quando necessário. A seguinte pesquisa tem por objetivo analisar sistema estomatognático de sujeitos de três a 12 anos, pré cirurgia, por meio de três fontes de dados que são: anamnese, protocolo de Avaliação Miofuncional Orofacial com Escores Resumido (AMIOFE) e Biofeedback Pró-Fono: Pressão de Lábios e de Língua-PLL Pró-Fono®, visando relacionar os dados obtidos sobre as estruturas estomatognáticas da língua e lábios desses sujeitos. Nos resultados obtidos foi observada diferença entre as médias de força de língua e lábios do grupo estudo (GE) e grupo controle (GC), sendo que o GE tem médias menores, indicando força reduzida. GE também tem maior queixa de falta de ar durante a noite do que GC. Como conclusão, podemos perceber que há impacto dessas alterações na qualidade de vida, principalmente na qualidade do sono, assim como força reduzida de lábios e língua no grupo estudo o que pode ocasionar alteração de mastigação, deglutição e do padrão de crescimento craniofacial.

\section{Palavras-chave:}

Respiração oral, força de lábio, força de língua

\section{Introdução}

A respiração oral $(\mathrm{RO})$ impacta nas estruturas estomatognáticas e suas funções, gerando características em comum entre esses sujeitos, como é descrito na literatura1. Além disso, esse padrão respiratório impacta na qualidade de vida, como por exemplo, problemas escolares, cansaço e cefaléia ${ }^{12}$.

Considerando os parâmetros de alterações causados pela respiração oral, também é visto na literatura que essas alterações podem ser consequências de outros fatores, não somente RO, como hábitos deletérios, sendo possível observar alterações na língua, lábios e arcada dentária ${ }^{3}$.

Por isso, esse estudo tem como objetivo analisar a partir de três fontes de dados diferentes as estruturas estomatognáticos lábios e língua, fazer a comparação entre elas para compreender se há ligação entre dados da anamnese, Avaliação miofuncional oral utilizando o protocolo de Avaliação Miofuncional Orofacial com Escores Resumido (AMIOFE) e Biofeedback Pró-Fono®: Pressão de Lábios e de Língua-PLL Pró-Fono.

\section{Resultados e Discussão}

A coleta de dados foi realizada com crianças de três até 12 anos com hipertrofia de tonsilas palatina e faríngea (GE) e com um grupo de controle (GC), sendo 35 sujeitos no GE e 35 no GC. Os resultados foram obtidos por meio de uma anamnese, protocolos AMIOFE e PLLque foram gravados no computador ou por registro de fotos.

Os dados foram tabulados e tratados estatisticamente. No GE foi observado que as medidas de pressão de lábios são menores que a de GC, sendo considerado para análise a média das três medidas feitas dessa mesma estrutura. As médias de pressão de dorso também são maiores em GC, enquanto que nas médias de ponta de língua os dados não são tão diferentes entre os grupos. Esses dados indicam que a força de língua e lábios no GE é menor do que em GC.

Além disso, foi observado que crianças com hábitos deletérios de chupeta e mamadeira tiveram médias de pressão de lábios e língua mais baixas ou então a criança não conseguia realizar força necessária para mensurar no aparelho.

No GE também foi observado que as crianças têm maior recorrência na falta de ar durante a noite e maior tempo de aleitamento materno, de acordo com dados colhidos na anamnese.

Nos dados do protocolo AMIOFE não foram observadas mudanças significativas tanto em GE quanto em GC nas estruturas estomatognáticas e suas funções, assim como mobilidade também estava preservada nos dois grupos.

\section{Conclusões}

Esses dados indicam que o grupo estudo tem sujeitos que, devido a respiração oral, estão tendo sua qualidade de vida afetada, considerando dados da qualidade de sono da anamnese, em que é relatada falta de ar noturna com frequência. É visto também a presença de hábitos deletérios (chupeta e mamadeira) em crianças do GE e GC, o que pode repercurtir em alterações futuras das estruturas estomatognáticas. Apesar da força reduzida nos sujeitos de GE, a mobilidade não apresenta alteração e o tempo de aleitamento materno foi maior em GE do que em GC.

\section{Agradecimentos}

Agradecimentos ao apoio do CNPq e a participação do AME de Santa Bárbara D'Oeste.

\footnotetext{
1 Veron, H. L. et al. Implicações da Respiração Oral na Função Pulmonar e Músculos Respiratórios. Revista CEFAC. São Paulo, v. 18, n. 1, p. 242-251, 2016.

${ }^{2}$ Chedid, K. A. K. et al.. A Influência da Respiração Oral no Processo de Aprendizagem da Leitura e Escrita em Crianças Pré-Escolares. Revista Psicopedagogia. São Paulo, v. 21, n. 65, p. 157-163. 2004.

${ }^{3}$ Melo, P. E. D.; PONTES, J. R. S.. Hábitos Orais Deletérios em um Grupo de Crainças de uma Escola da Rede Pública na Cidade de São Paulo. Revista CEFAC. São Paulo, v. 16, n. 6, p. 1945-1952, 2014.
} 